\title{
PENGGUNAAN LIMBAH KULIT SAMAK KROM PADA KEMASAN PRODUK OLAHAN KAYU GAHARU
}

\author{
Agung Wicaksono ${ }^{1}$ \\ (Jurusan Kriya, Fakultas Seni Rupa, ISI Yogyakarta, jokja09@gmail.com, 087738902802) \\ Retno Purwandari² \\ (Jurusan Kriya, Fakultas Seni Rupa, ISI Yogyakarta, enousagi@gmail.com, 083869258047)
}

\begin{abstract}
This research needs to be carried out to help improve the people's economy. Stems from seeing the availability of chromium leather waste in Magetan that is not utilized properly. $O n$ the other hand, there is a quality product that is processed products of agarwood in West Kalimantan, especially in the CV Global Agarwood Station but not selling because the packaging is not designed to be attractive. Agarwood can be processed into chips, oils that can be used for aromatherapy and parfume, and agarwood sculpture. Therefore, this research is expected to be able to realize the packaging of agarwood processed wood products by considering the composition of the design elements of the chrome tanned leather waste material in Magetan. This research method uses the flow or stages, namely predesign, design, embodiment, and presentation. Chrome leather packaging products produced apply the composition of design elements from two cultures in West Kalimantan, namely Dayak and Malay with hand sewing techniques, machine sewing, laser, and punching. Cultural elements of both, such as flora, specificity of the ornaments, and the specificity of colors appearing on the product packaging. This product packaging is expected to increase the selling value of agarwood processed wood products.
\end{abstract}

Keywords: chrome tanned leather waste, gaharu wood processed products, product packaging

\begin{abstract}
Abstrak
Penelitian ini perlu dilaksanakan untuk membantu peningkatan perekonomian rakyat. Bermula dari melihat ketersediaan limbah kulit samak krom di Magetan yang tidak dimanfaatkan dengan baik. Di lain hal, ada suatu produk berkualitas yakni produk olahan kayu gaharu yang ada di Kalimantan Barat khususnya di CV Global Agarwood Station tetapi kurang menjual karena kemasannya tidak dirancang menarik. Kayu gaharu dapat diolah menjadi serpihan kayu (chip), minyak yang bisa dimanfaatkan untuk aromaterapi dan parfum, serta agarwood sculpture. Untuk itu, melalui penelitian ini diharapkan mampu mewujudkan kemasan produk olahan kayu gaharu dengan mempertimbangkan komposisi elemen desain dari bahan limbah kulit samak krom yang ada di Magetan. Metode penelitian ini menggunakan alur atau tahapan, yakni: praperancangan, perancangan, perwujudan, dan penyajian. Produk kemasan berbahan kulit samak krom yang dihasilkan mengaplikasikan komposisi elemen desain dari dua budaya yang ada di Kalimantan Barat, yaitu Dayak dan Melayu dengan teknik jahit tangan, jahit mesin, laser, dan punching. Unsur-unsur budaya dari keduanya, seperti flora, kekhasan ornamen, dan kekhasan warna dimunculkan pada kemasan produknya. Dengan kemasan produk ini diharapkan menambah nilai jual produk olahan kayu gaharu.
\end{abstract}

Kata Kunci: limbah kulit samak krom, produk olahan kayu gaharu, kemasan produk 


\section{PENDAHULUAN}

Kayu gaharu adalah kayu yang berwarna kehitaman dengan kekhasannya mengandung resin dan berbau harum. "Gaharu which is also known as agarwood or aloeswood is a fragrant resinous heartwood that is usually derived from diseased timber of the genus Aguilaria (Thymelaeaceae)" (Azah,

2013: 213). Terdapat beberapa spesies kayu Gaharu di Indonesia dikenal dengan nama spesies Aquilaria

hilata, Aquilaria microcarpa, Aquilaria cumingiana, dan Aquilaria beccarain. Nama "gaharu" ini sendiri merupakan istilah yang diberikan atas respon tanaman terhadap infeksi mikroba yang masuk pada luka jaringan kayu. Mikroba yang masuk ke jaringan kayu menyebabkan tanaman mengeluarkan senyawa fitoaleksin yang berfungsi sebagai imunitas tanaman. Sifat senyawa tersebut berwarna coklat dan berbau harum.

Nilai ekonomi kayu ini cukup tinggi terutama untuk gaharu jenis beringin (nama istilah gaharu dalam perdagangan) dengan kadar resin relatif tinggi. Salah satu daerah penghasil kayu gaharu di Indonesia adalah Pulau Kalimantan yang memiliki hutan cukup lebat. Indonesia membatasi perdagangan kayu gaharu alam dengan mengacu pada konvensi CITES (Convention on International Trade in Endangered Species).

Produk olahan kayu gaharu dapat berupa minyak gaharu, serpihan kayu, dan batang kayu. Minyak kayu gaharu digunakan sebagai aroma pewangi untuk bahan baku produk parfum. Serpihan kayu gaharu juga digunakan untuk aroma terapi atau bahan baku aksesori fesyen. Warna kayu gaharu yang berwarna hitam kecoklatan menarik untuk dibuat aksesori, seperti gelang atau kalung. Batang kayu gaharu sering dijadikan hiasan koleksi karena bentuk serat yang dihasilkan dari mikroba sangat menarik. Kayu jenis ini biasanya diburu oleh kolektor dengan harga cukup tinggi. Bahkan masyarakat Manokwari memanfaatkan daun gaharu sebagai pembungkus makanan karena beraroma harum dan menambah selera makan (Dimara, 2011: 38).

Beberapa pengusaha menjual
produk olahan kayu gaharu tanpa
kemasan belum banyak dijual dengan kemasan yang memberikan nilai tambah ekonomi. Sebenarnya daya saing produk ini dapat ditingkatkan melalui pengemasan produk. Penelitian ini dilakukan untuk membuat perancangan kemasan yang dapat memberikan nilai tambah bagi produk terutama dari sisi perlindungan produk dan branding. Perubahan desain dilakukan karena faktor perubahan teknologi, perilaku konsumen yang selalu berkembang, dan nilai estetik yang dinamis. Daya saing produk sangat ditentukan pada ketepatan antisipasi perubahan. Keberhasilan inovasi desain terletak pada kapasitas SDM-nya. Langkah awal yang perlu dilakukan adalah kemauan untuk selalu bereksperimen terhadap desain produknya. Keunggulan inovasi desain dapat diukur dari konsep dan kualitas produknya (Wicaksono, 2014: 15-16).

Kemasan produk dipilih menjadi topik penelitian dengan alasan untuk menambah nilai kemenarikan (attractiveness) dari produk yang dikemas. "Menarik merupakan kesesuaian antara properti yang dimiliki objek estetis dengan nilai estetis yang dipakai subjek estetis" (Junaedi, 2016: 17). Kemenarikan yang ingin dicapai ialah 
untuk kemenarikan kemasan produk olahan kayu gaharu. Pada penelitian ini kemasan kayu gaharu dari CV Global Agarwood Station digunakan sebagai objeknya. Pemilihan objek ini didasari pada survei awal bahwa perusahaan ini telah menggunakan kemasan tetapi dirasakan masih kurang maksimal dalam penampilannya.

Masyarakat memiliki kebutuhan yang dapat menjadi variabel dalam memilih gaya hidupnya. Produk kriya mampu memberikan nilai sosial dan ekonomi bagi masyarakat. Kriya berkembang sesuai dengan masanya, saat ini kriya memiliki peran dalam masyarakat kontemporer maupun tradisional. Perkembangan teknologi, misalnya teknologi digital, banyak memengaruhi bentuk-bentuk produk dan metode pembuatannya. Perkembangan teknologi ini banyak menimbulkan diskusi menarik bagi perkembangan kriya (Wicaksono, 2018: 147-148). Perancangan ini merupakan salah satu upaya untuk menghasilkan produk-produk kriya yang memiliki basis pada budaya nusantara. Dalam dunia industri kreatif, upaya ini merupakan dorongan bagi tumbuhnya kreativitas dan mewujudkannya dalam bentuk produk yang diminati oleh pasar. Penggalian terhadap nilai-nilai budaya lokal memiliki peluang pasar yang cukup menjanjikan bagi pengembangan produk kriya. Pertautan antara nilai-nilai luhur budaya masyarakat dengan kebutuhan masa kini dapat mendorong tumbuhnya rancangan-rancangan baru yang memberikan inspirasi terhadap penyelesaian permasalahan dunia (Wicaksono, 2009: 208-209).

Pada sisi lain, terdapat bahan sisa kulit samak krom yang cukup banyak di daerah sentra industri kulit Kabupaten Magetan. Bahan kulit ini memiliki $\begin{array}{llr}\text { karakter khas pada } & \begin{array}{r}\text { tekstur } \\ \text { permukaan }\end{array} \\ \text { dan } & \text { kelembutan }\end{array}$ pegangannya. Sejak lama bahan kulit dikenal sebagai bahan baku produk dengan nilai ekonomi yang cukup tinggi untuk keperluan fesyen, interior, atau perabot lainnya.

Industri kulit di Kabupaten Magetan banyak menghasilkan limbah atau sisa-sisa kulit dari pembuatan tas dan sepatu. Sementara ini sisa-sisa kulit tersebut belum termanfaatkan dengan baik. Perajin kulit banyak menjual sisa-sisa kulit dengan harga sangat murah dan tidak sedikit yang membuangnya. Potensi ini dapat dimanfaatkan dengan membuat inovasi produk yang mampu memberikan nilai tambah bagi pemanfaatan limbah tersebut. Limbah yang dimaksud lebih ke limbah kulit samak krom. Kulit samak adalah kulit hewan yang telah diubah secara kimiawi guna menghasilkan bahan yang kuat, lentur, dan tahan dari pembusukan (Setyaningsih, 2017: 76).

Terkait dengan beberapa fenomena di atas, dapat dirangkai suatu hubungan saling menguntungkan antara kebutuhan kemasan produk olahan kayu gaharu dengan memanfaatkan limbah kulit yang dihasilkan oleh sentra industri kulit. Jika terjadi koneksi antara kebutuhan dan ketersediaan, langkah inovasi dalam perancangan suatu produk akan memberikan nilai tambah bagi keduanya. Berkaitan dengan uraian dan penjelasan tersebut di atas, penelitian ini merancang kemasan untuk produk olahan kayu gaharu dengan menggunakan limbah kulit samak krom.

Saat ini perancangan produk tidak dapat terlepas dari kebutuhan pasar. Kebutuhan pasar sangat dipengaruhi oleh 
perubahan perilaku individu dalam masyarakat yang terakumulasi menjadi kecenderungan gaya hidup (lifestyle trends). Pola-pola perilaku dapat terbaca dengan menggunakan alat prediksi gaya hidup (trends forecasting). Indikator ini banyak digunakan oleh perusahaan-perusahaan dalam melakukan inovasi desain produknya.

Dalam dunia manajemen, perubahan yang berbasis pada kebutuhan pasar sering disebut dengan istilah market driven. Jika dikonversi menjadi pertimbangan-pertimbangan desain, perilaku konsumen merupakan data penting dalam membangun konsep perancangannya. Hal ini memerlukan metode perancangan yang tepat agar diperoleh hasil inovasi produk sesuai dengan kebutuhan pasar. Kesesuaian ini perlu dilengkapi dengan pertimbangan pemilihan segmentasi, penetapan target, dan pemantapan positioning.

Kemasan merupakan salah satu perangkat yang digunakan untuk melindungi produk dan juga digunakan untuk media branding bagi produk. Peran kemasan dalam pemasaran adalah alat komunikator kepada konsumen yang dapat menarik perhatian di antara kerumunan kompetisi produk. Pergeseran perilaku konsumen dapat diamati dengan berubahnya fungsi produk menjadi atribut yang dapat merepresentasikan status sosial, pengokohan karakter pribadi, dan keperluan ekspresi pribadi lainnya.

Untuk itu, kegiatan ini ditujukan untuk mengaplikasikan elemen-elemen desain yang diperlukan dalam perancangan kemasan produk olahan kayu gaharu dari bahan limbah kulit samak krom. Perancangan yang dihasilkan tersebut diwujudkan menjadi kemasan produk olahan kayu gaharu dari bahan limbah kulit samak krom. Perancangan dan pewujudan kemasan produk olahan kayu gaharu ini diharapkan mampu memberikan sumbangan bagi perkembangan ilmu pengetahuan dalam bidang seni, khususnya yang terkait dengan perihal kemasan produk. Lebih luas lagi, kegiatan ini mampu mengembangkan ilmu pengetahuan dan dapat menjadi acuan berharga dalam penelitian lebih lanjut. Harapannya, penelitian ini menyumbang manfaat bagi dunia industri, khususnya industri produk olahan kayu gaharu dan kulit.

\section{METODE}

Metode penelitian yang digunakan dititikberatkan pada penelitian penciptaan karya yang objeknya merupakan kebutuhan dari masyarakat perajin kulit dan produk olahan kayu gaharu. Penelitian ini bisa dikatakan sebagai tindak lanjut dari sebuah kasus yang memunculkan peran serta atau bisa disebut sebagai penelitian peran serta. Penelitian peran serta ini termasuk sebagai penelitian terapan yang bisa dipakai dalam bidang seni rupa dan desain (Sumartono, 2017: 259). Menurut Hendriyana (2018: 33-34), metode penelitian seni rupa pada umumnya tidak ada teori model tunggal karena karakteristik seni rupa unik dan khas tergantung objek dan subjek penelitian. Salah satu metode yang dapat digunakan untuk penelitian ini dapat mengikuti alur yang dijelaskan sebagai berikut :

1) Tahap praperancangan merupakan tahapan eksplorasi data, isu yang relevan, dan permasalahan yang dihadapi masyarakat. Pada tahap ini peneliti juga mengembangkan imajinasi dan 
merasionalisasikannya melalui teori-teori, data pustaka, atau karya sebelumnya. Data diperoleh dengan cara observasi langsung dan wawancara atau melihat objek lainnya. Data tersebut dianalisis dengan cara dideskripsikan secara verbal. Deskripsi data digunakan untuk memahamai permasalahan secara komprehensif. Data yang sudah dideskripsikan akan diseleksi untuk menentukan korelasi antardata yang mendukung pembuatan konsep perancangan. Analisis akan didasarkan pada bentuk (visual), fungsi, dan makna untuk mendapatkan konfigurasi harmonis antara ketiga hal tersebut. Alat yang digunakan dalam analisis ini adalah mood board, yaitu penyusunan data visual dan verbal yang memudahkan pemahaman korelasi antardata. Hasil analisis tersebut dilanjutkan dengan penyusunan perancangan yang menghasilkan sketsa, gambar teknis, pola, alur produksi, costing, dan standar kualitas produk. Tujuan dan konsep dasar penelitian dapat dikerjakan pada tahap ini.

2) Tahap perancangan merupakan tahapan pembuatan deskripsi verbal dari analisis pada tahap pertama yang divisualisasikan dengan berbagai pertimbangan. Gagasan visual ini dapat diwujudkan dalam bentuk prototipe dengan pertimbangan bentuk, nilai, fungsi, dan makna.

3) Tahap pewujudan merupakan tahapan realisasi dari hasil uji kelayakan terhadap prototipe, sehingga wujud kemanfaatan prototipe jelas terlihat fokus dan sasarannya.
4) Tahap penyajian merupakan tahapan mengomunikasikan dengan masyarakat luas. Tahapan ini terjadi dialog dan apresiasi dari masyarakat yang diharapkan dapat menyempurnakan objek pada penelitian lanjutan.

\section{HASIL DAN PEMBAHASAN}

\section{a. Produk Olahan Kayu Gaharu}

Kayu gaharu merupakan hasil reaksi tanaman terhadap mikroba yang masuk ke dalam batang kayu. Reaksi ini menghasilkan sejenis resin yang memiliki ciri khas pada baunya. Resin ini diambil sebagai bahan dasar kosmetik dan parfum yang disukai sejak zaman dahulu. Bahan kayu gaharu ini berwarna gelap, seperti kehitaman atau kecoklatan.

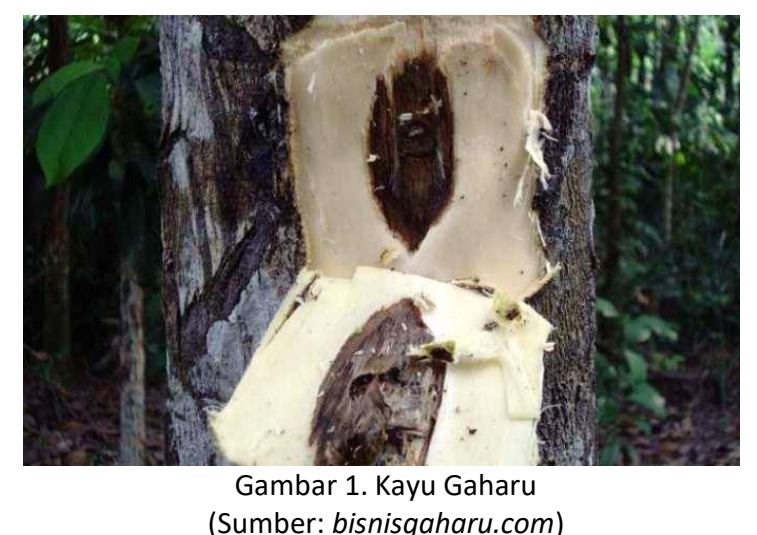

Salah satu olahan kayu gaharu yang banyak diperjualbelikan adalah serpihan kayu yang sering disebut dengan istilah chip. Ukuran bervariasi mulai dari $2 \mathrm{~cm} \times 4 \mathrm{~cm}$ dengan ketebalan $1 \mathrm{~cm}$ dan bentuk tidak beraturan. Contoh serpihan kayu gaharu tersebut adalah contoh yang diberikan untuk keperluan perancangan kemasan pada penelitian terapan ini. Selama ini serpihan kayu gaharu dijual tanpa menggunakan kemasan khusus, hanya menggunakan plastik atau kertas koran. Harga kayu gaharu yang dijual CV Global Agarwood Station mulai dari 
Rp2.000.000, 00 - Rp 15.000.000, 00 per kilogram.

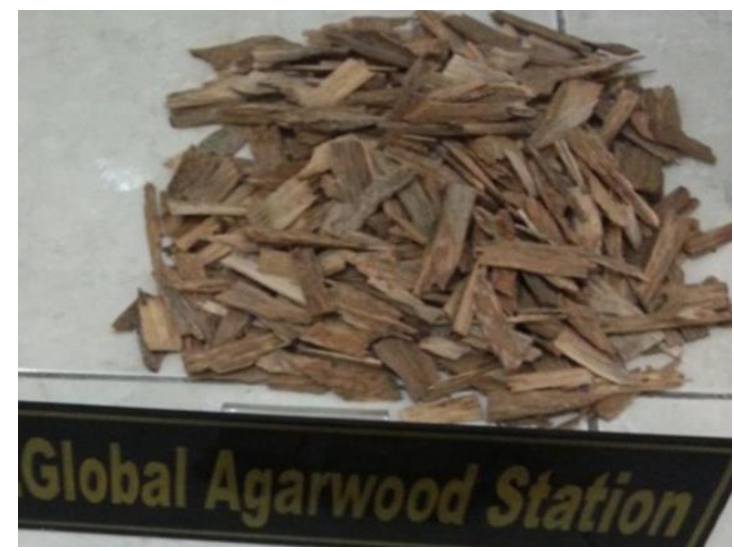

Gambar 2. Serpihan Kayu Gaharu (Sumber: CV Global Agarwood Station)

Beberapa konsumen kayu gaharu sering menyimpan serpihan (chip) untuk dinikmati aroma wanginya. Sifat kayu gaharu seperti kayu cendana yang mengeluarkan aroma wangi dalam jangka waktu relatif lama. Kegunaan lain adalah bahan campuran dupa yang dibuat serbuk dan dicetak berbentuk silinder kecil menyerupai lidi. Kayu ini juga sering diambil minyaknya untuk essential oil yang sering digunakan sebagai bahan dasar obat, kosmetik, dan parfum. Harga minyak kayu gaharu yang dijual CV Global Agarwood Station mulai dari Rp300.000, 00 - Rp500.000, 00 per $50 \mathrm{ml}$.

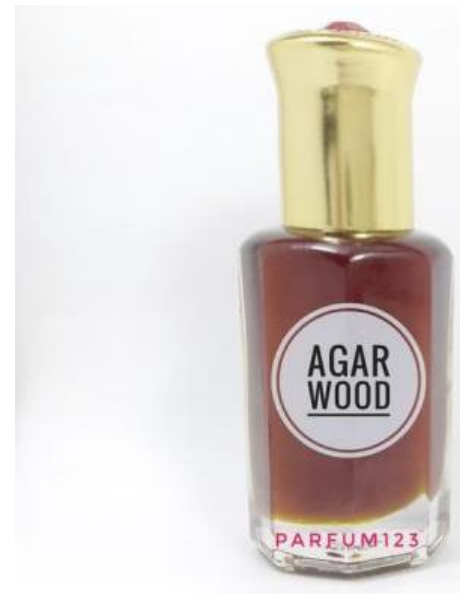

Gambar 3. Botol Minyak Parfum Kayu Gaharu (Sumber: CV Global Agarwood Station)
Saat ini kemasan yang sudah digunakan untuk mengemas produk olahan kayu gaharu terbuat dari kayu berbentuk kotak dengan berbagai macam ukuran.

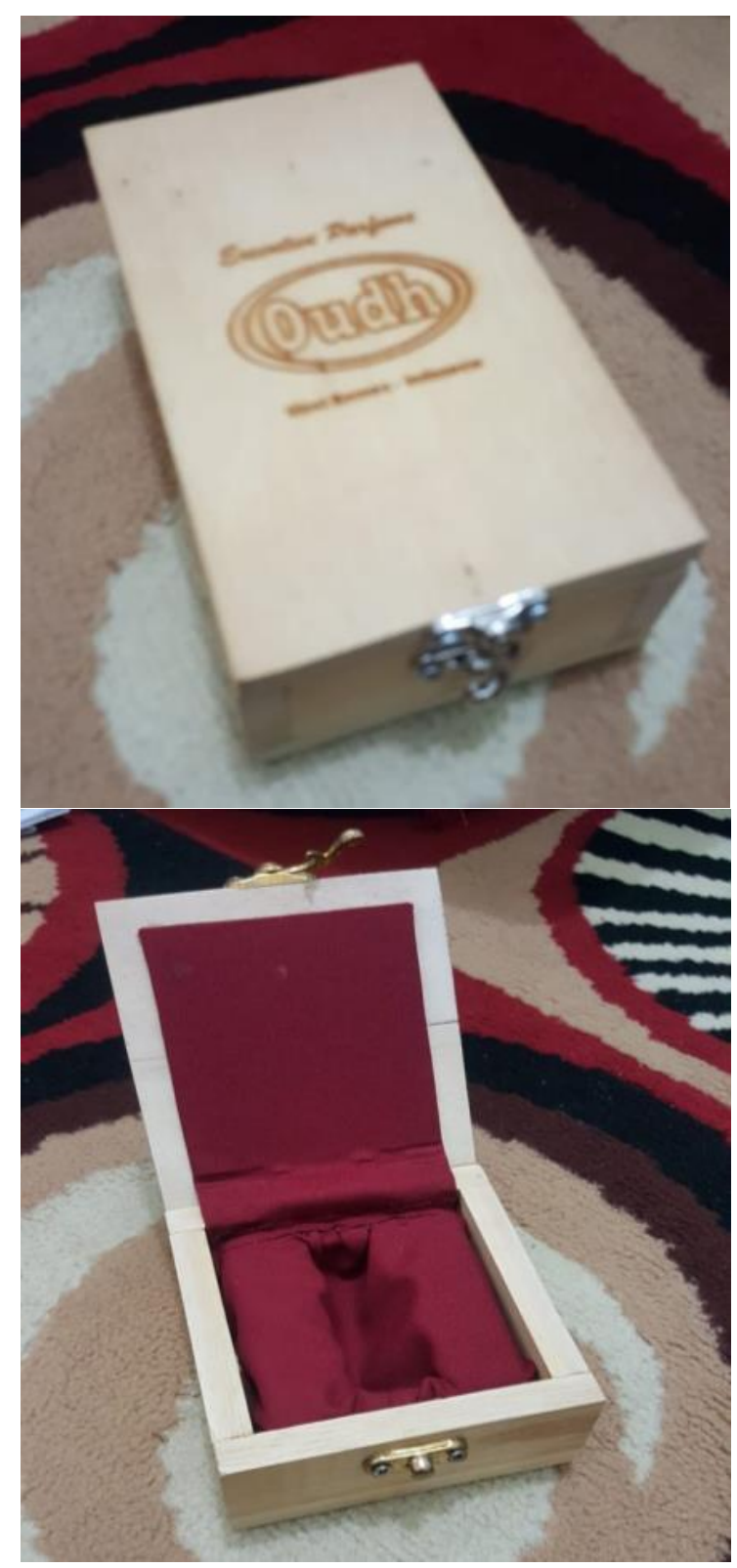

Gambar 4. Kemasan Kayu CV Global Agarwood Station

Limbah kulit samak krom di Kabupaten Magetan berasal dari industry kerajinan tas dan alas kaki. Pada penelitian ini digunakan limbah kulit samak krom dari industri kerajinan tas. Pertimbangan penggunaan limbah kulit ini didasarkan pada karakter kulit yang dihasilkan, 
seperti ukuran limbah, tekstur, warna, dan kelemasan kulit (softness).

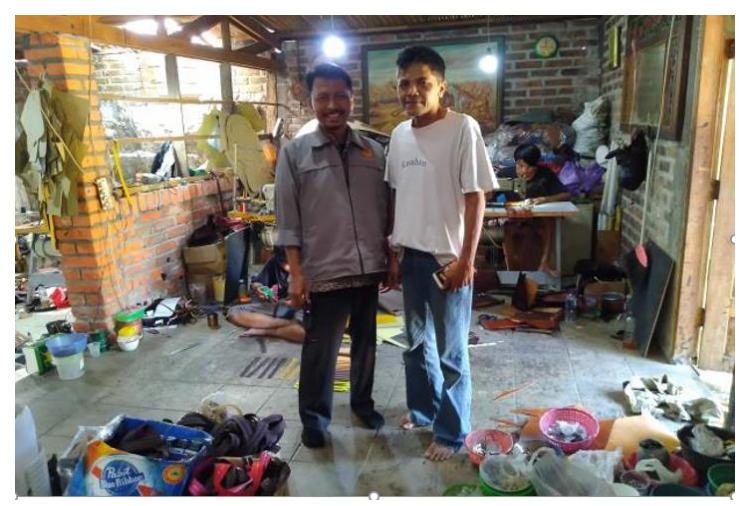

Gambar 6. Kunjungan ke Industri Kerajinan Tas “D’War” di Kabupaten Magetan

(Sumber: Dokumentasi Agung Wicaksono)

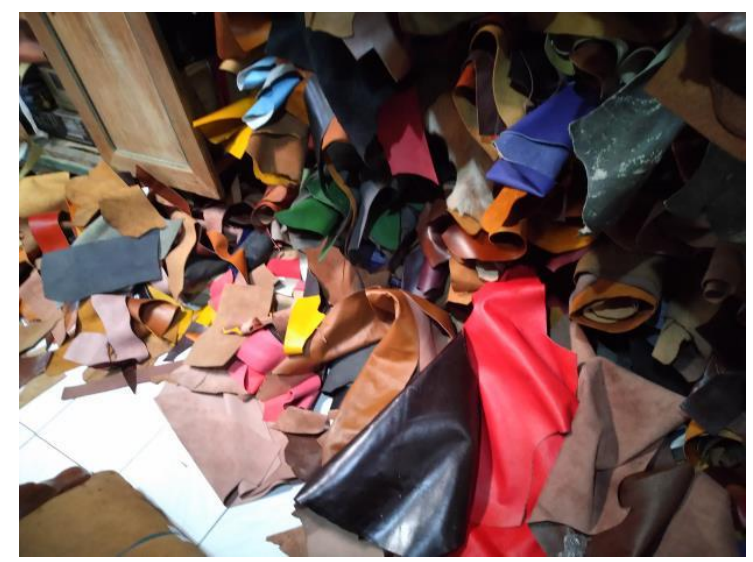

Gambar 7. Limbah Kulit Samak Krom

(Sumber: Dokumentasi Agung Wicaksono)

\section{c. Pra-Perancangan}

Tahapan pra-perancangan merupakan tahapan awal yang berisi tentang penggalian data (data primer dan sekunder), pembuatan mind mapping, dan penyusunan konsep. Tahapan ini digunakan untuk dasar pertimbangan dalam membuat perancangan suatu produk. Data dikumpulkan melalui kegiatan observasi, wawancara, dan studi referensi. Data pokok sudah diambil seperti pada tulisan sebelumnya, yaitu tentang produk yang dikemas dan material limbah kulit samak krom.

Data lain yang diperlukan adalah target dan perilaku konsumen yang diambil dari informasi trend forecasting (prediksi tren) tahun 2019/2020. Bekraf mengeluarkan informasi data tren yang mengambil tema besar "Singularity". Tren ini berbicara tentang pengaruh kuat global yang masuk ke seluruh lini kehidupan. Di Indonesia pengaruh ini membangkitkan semangat berkarya dalam jati diri yang kokoh. Hal ini dapat dilihat pada perkembangan produk-produk lokal yang mulai dapat bersaing dengan produk luar.

Subtema yang dipotret oleh Indonesian Trend Forecasting Bekraf adalah "Upskill Craft", yaitu transformasi dari kerajinan tradisional menjadi produk yang dibutuhkan oleh konsumen sekarang. Ciri khas subtema ini adalah bahan natural, dikerjakan dengan keterampilan tangan, pemberdayaan masyarakat, dan kolaborasi elemen glokal (global-lokal).

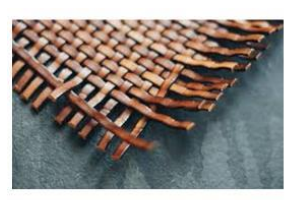

\section{Upskill Craft}

Natural Material

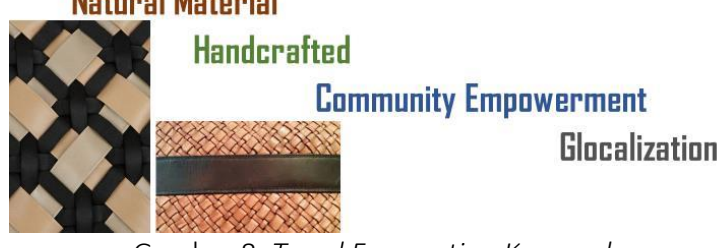

Gambar 8. Trend Forecasting Keyword

Elemen lokal diangkat dari kebudayaan Melayu dan Dayak yang tumbuh di Kalimantan Barat. Alasan kuat pengambilan elemen ini adalah produk olahan kayu gaharu berasal daerah kawasan tersebut. Kebudayaan yang berkembang di Kalimantan Barat didominasi oleh kebudayaan-kebudayaan yang berasal dari beberapa suku, seperti Dayak dan Melayu. Kebudayaan ini secara harmonis telah berdampingan dalam kurun waktu lama. Kekayaan budaya ini diaplikasikan dalam penyusunan konsep perancangan. 


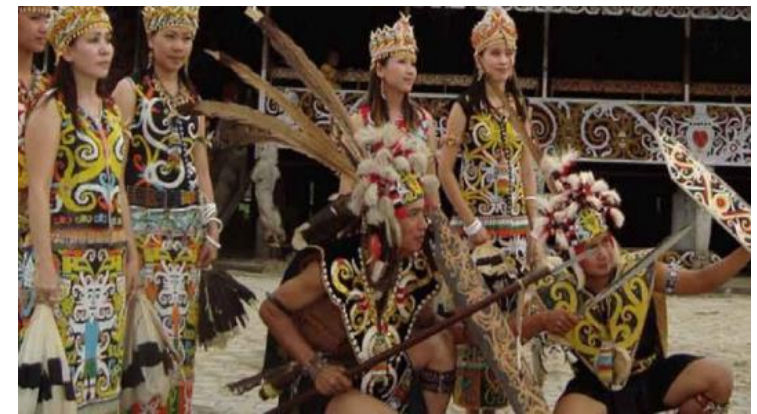

Gambar 9. Masyarakat Adat Suku Dayak di Kalimantan Barat

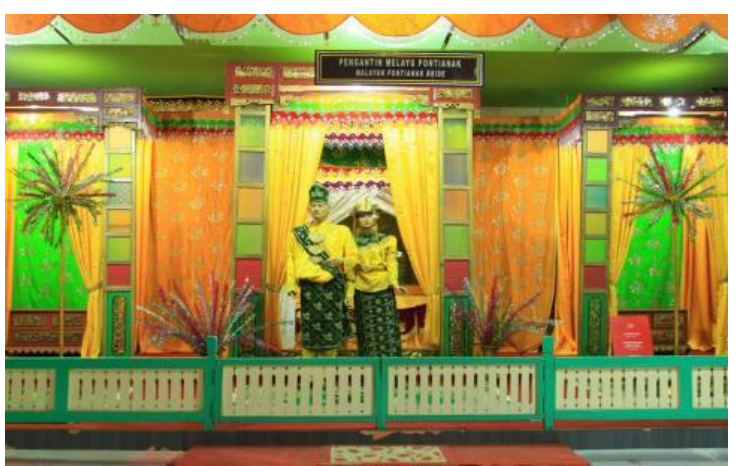

Gambar 10. Kebudayaan Melayu Kalimantan Barat

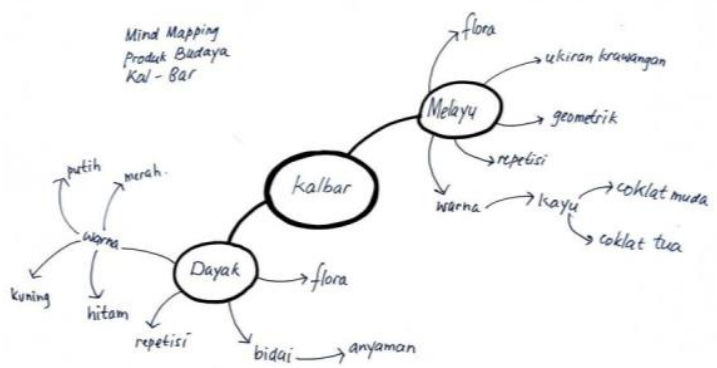

Gambar 11. Mind Mapping Produk Budaya Kalimantan Barat

Prediksi konsumen perlu dilakukan untuk mengetahui penggunanya. Produk olahan kayu gaharu memiliki harga relatif mahal jika dibandingkan dengan parfum yang dijual di toko-toko parfum. Bau wangi yang dikeluarkan sangat khas cenderung berselera eksotik. Konsumen yang menyukai bau kayu gaharu cenderung menyukai tema-tema etnik dan klasik. Prakiraan usia pemakainya sekitar 40 tahunan ke atas yang memiliki kematangan emosi dan status social relatif mapan. Secara visual penggambaran konsumen tersebut dapat dilihat pada gambar grafis di bawah ini.

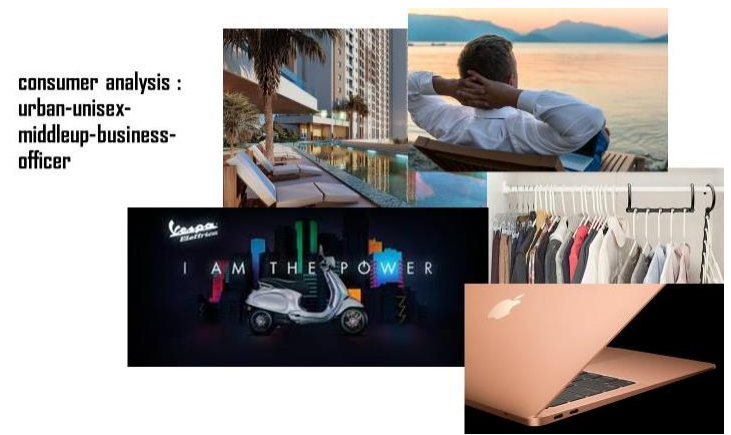

Gambar 12. Visualisasi Prediksi Konsumen Produk Olahan Kayu Gaharu

Konsep dibangun dengan memahami objek dan penggunanya dengan emperhatikan secara komprehensif konteks gaya hidupnya.

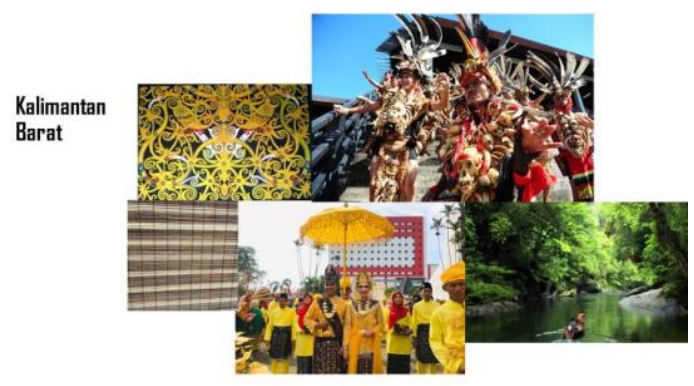

Gambar 13. Visualisasi Kalimantan Barat

\section{d. Perancangan}

Tahapan perancangan dimulai dari pembuatan sketsa alternatif sebagai visualisasi konsep yang telah dibuat pada tahapan pra-perancangan.

\section{e. Pewujudan}

Tahap pewujudan merupakan tahapan yang merealisasikan perancangan kemasan. Tahapan ini dimulai dari pemolaan, pemotongan (cutting), penyesetan (skiving), penjahitan (sewing), perakitan (assembling), dekorasi, dan finishing.

Sebelum melakukan proses perwujudan perlu disiapkan alat dan bahan. Jenis alat dan bahan yang diperlukan disesuaikan dengan perancangan produknya. 
Tabel 1. Tabel Alat

\begin{tabular}{|l|l|l|}
\hline No & Nama Alat & Fungsi \\
\hline 1 & $\begin{array}{l}\text { Bolpoin Tinta } \\
\text { Perak }\end{array}$ & $\begin{array}{l}\text { penanda batas pola di atas } \\
\text { lembaran kulit }\end{array}$ \\
\hline 2 & Pisau Cutter & memotong kulit \\
\hline 3 & Pisau Seset & menipiskan kulit \\
\hline 4 & Gunting & memotong benang \\
\hline 5 & Beveler & $\begin{array}{l}\text { membuat alur dan profil } \\
\text { tepi kulit }\end{array}$ \\
\hline 6 & Punching & melubangi kulit \\
\hline 7 & Chisel & pelubang jahit \\
\hline 8 & Palu & $\begin{array}{l}\text { pemukul punching, chisel, } \\
\text { dsb. }\end{array}$ \\
\hline 9 & Cutting Mat & landasan potong \\
\hline 10 & Block Wood & landasan pelubang \\
\hline 11 & Penggaris Besi & alat pelurus pemotongan \\
\hline 12 & Mesin Jahit & alat menjahit \\
\hline
\end{tabular}

Tabel 2. Bahan

\begin{tabular}{|l|l|l|}
\hline No & Nama Bahan & Spesifikasi \\
\hline 1 & Kertas Malaga & ukuran A3 \\
\hline 2 & Kulit & $\begin{array}{l}\text { limbah potong kerajinan } \\
\text { tas, samak krom }\end{array}$ \\
\hline 3 & Pelapis & kain suede \\
\hline 4 & Benang Jahit & Nilon \\
\hline 5 & Lem & Neoprene \\
\hline 6 & Aksesoris & Kancing \\
\hline 7 & Bahan Finishing & mink oil \\
\hline 8 & Cat Penampang & Veter \\
\hline 9 & Box Kayu & $\begin{array}{l}\text { albasia, ukuran box : } 12 \mathrm{~cm} \\
\times 8 \mathrm{~cm} \times 5 \mathrm{~cm}\end{array}$ \\
\hline
\end{tabular}

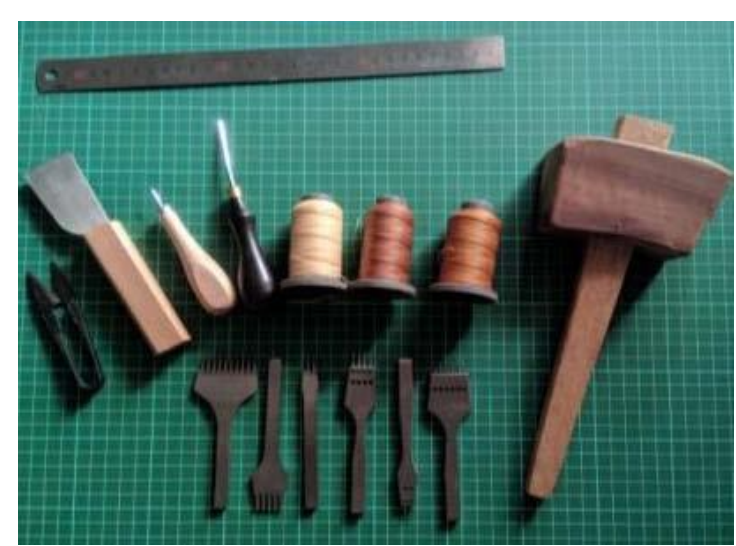

Gambar 14. Alat Produksi Jahit Tangan

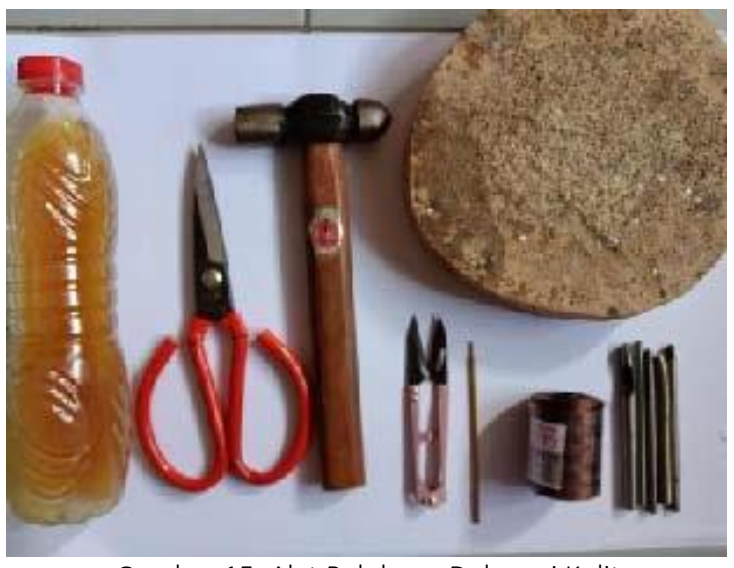

Gambar 15. Alat Pelubang Dekorasi Kulit

Pemolaan

dilakukan dengan memindahkan luasan bidang dari pola ke kulit. Kaidah pemolaan memperhatikan efisiensi dan menghindari defek-defek kulit. Arah kemuluran dan ketegangan kulit dapat diabaikan karena kemasan ini tidak mengalami tekanan dan tarikan saat pengoperasiannya.

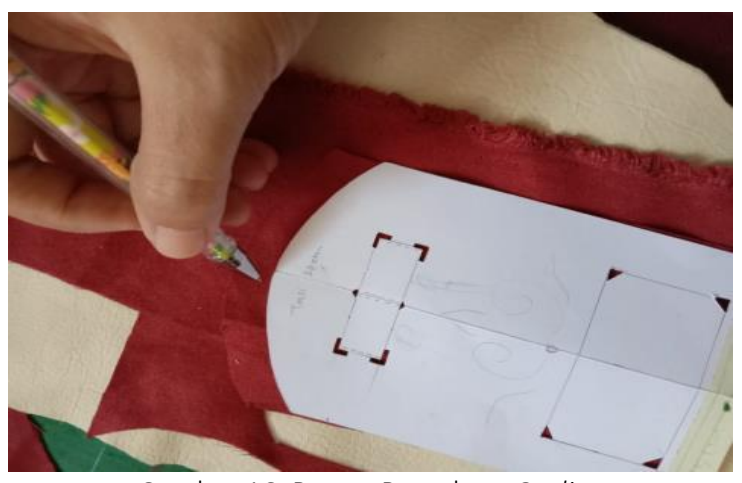

Gambar 16. Proses Pemolaan Outline

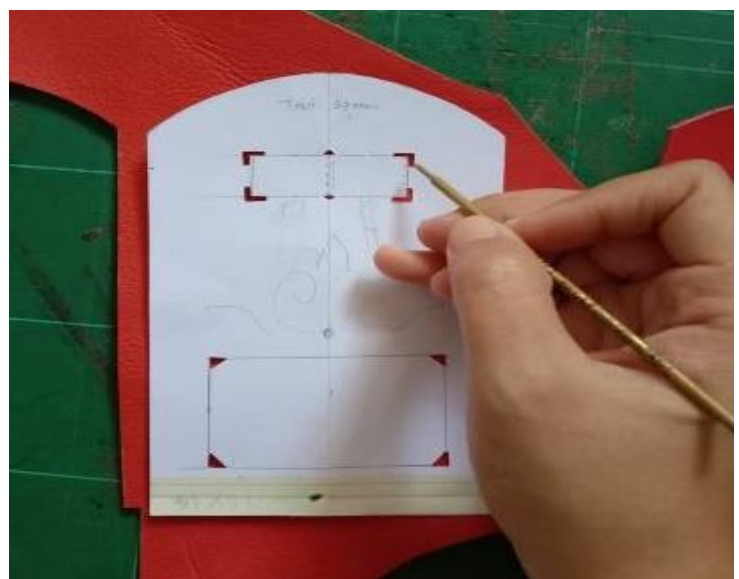

Gambar 17. Proses Pemolaan Marking 
Proses pemotongan dilakukan setelah proses pemolaan dan pemeriksaan ulang selesai. Proses pemotongan dilakukan dengan hati-hati agar diperoleh hasil potongan dengan ketepatan tinggi. Proses ini memengaruhi kemudahan proses penjahitan.

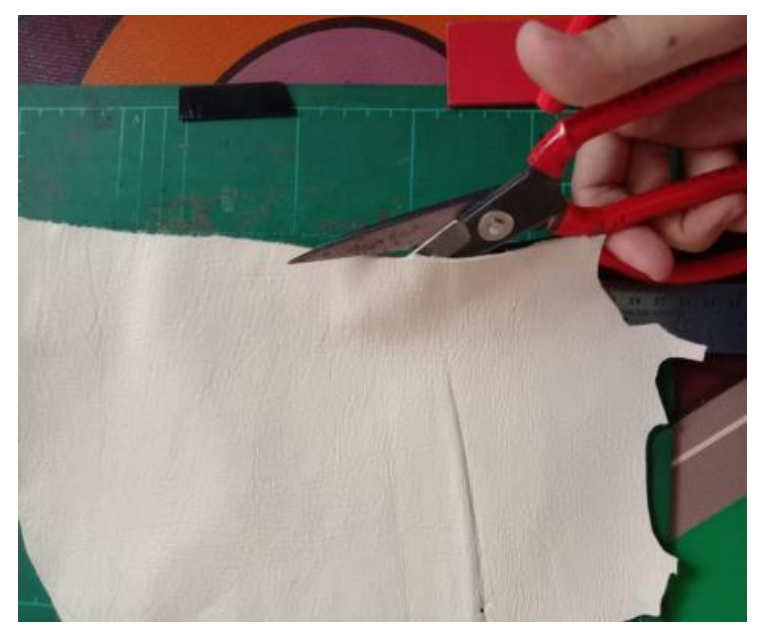

Gambar 18. Pemotongan Kulit

(Sumber: Dokumentasi Agung Wicaksono)

Kulit yang telah dipotong pada bagian tertentu diberi hiasan, salah satunya hiasan komposisi lubang. Proses menghias dengan bentuk-bentuk lubang dilakukan setelah proses potong. Alat yang digunakan untuk membuat lubang adalah punching. Operasional penggunaan alat ini dilakukan secara manual, yaitu dipukul dengan palu yang pada bagian daging (dalam) diletakkan pada landasan kayu.

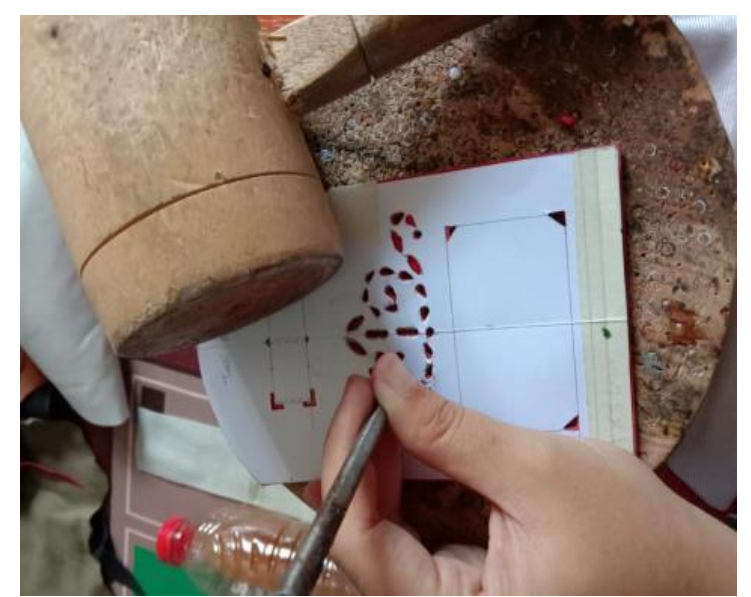

Gambar 19. Proses Menghias Kulit dengan Komposisi Lubang

(Sumber: Dokumentasi Agung Wicaksono)
Proses pembuatan dilanjutkan dengan penjahitan. Jahit yang digunakan terdapat dua jenis, yaitu jahit tangan dan jahit mesin. Perbedaan jenis jahitan ini terletak pada alat yang digunakan pada saat menjahit. Penampilan jahitan juga berbeda, mesin jahit menghasilkan jahitan yang lebih cepat dan rapi. Jahit tangan menghasilkan karakter jahitan handmade yang kuat. Kedua jenis jahitan ini dapat dipilih tergantung dari selera penggunanya.

Jenis jahitan yang digunakan adalah jahitan dengan jenis single needle dan jarak antarjahitan 2-3 mm per stitch. Model jahitan ini termasuk jenis moderat yang mudah diaplikasikan pada produk-produk kasual. Jenis kaitan benang jahit adalah jahit chain stitch yang termasuk jahitan sederhana tetapi cukup kuat untuk menjaga kaitan benang.

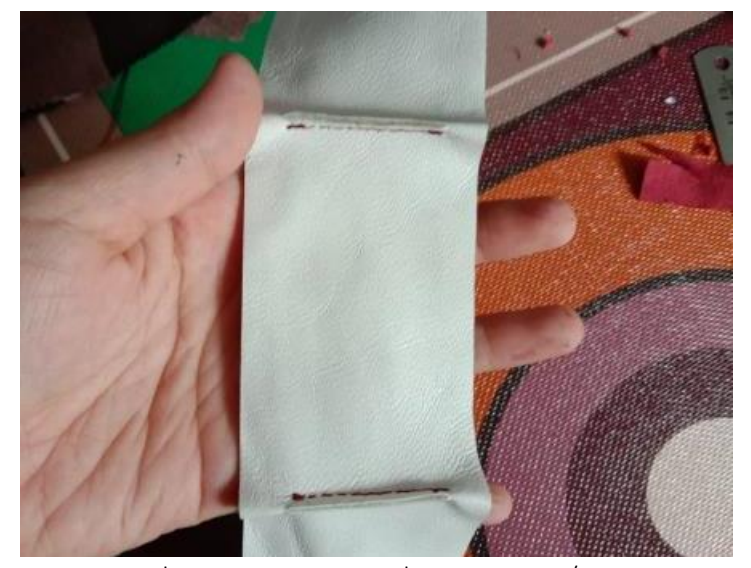

Gambar 20. Proses Perakitan Tepong/Gusset

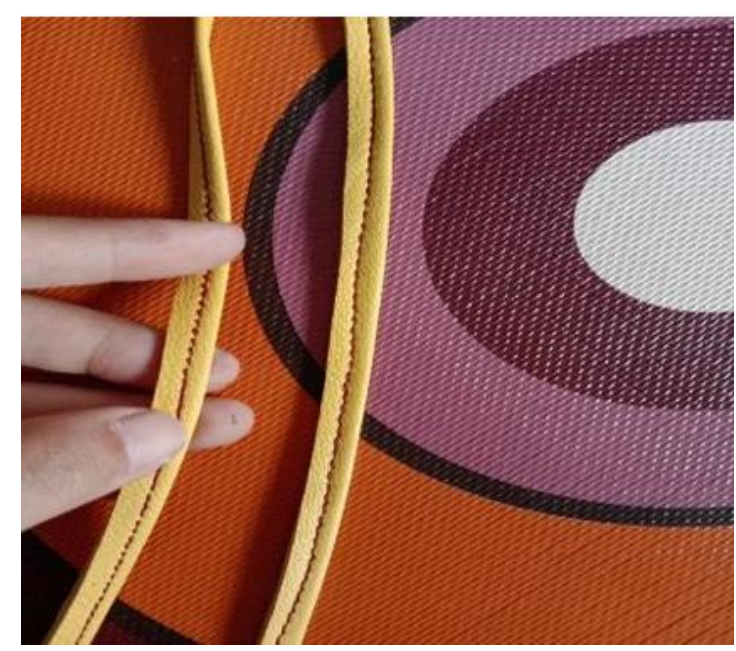

Gambar 21. Proses Penjahitan Tali Aksesori 
Tahap terakhir dalam pewujudan produk adalah finishing yang biasanya dilakukan perapian dan perlindungan terhadap bahan, misalnya pelapisan bahan silikon atau wax.

\section{f. Penyajian}

Hasil perwujudan dalam bentuk produk kemasan bahan kulit limbah untuk produk olahan kayu gaharu dapat dilihat pada gambar-gambar di bawah ini.

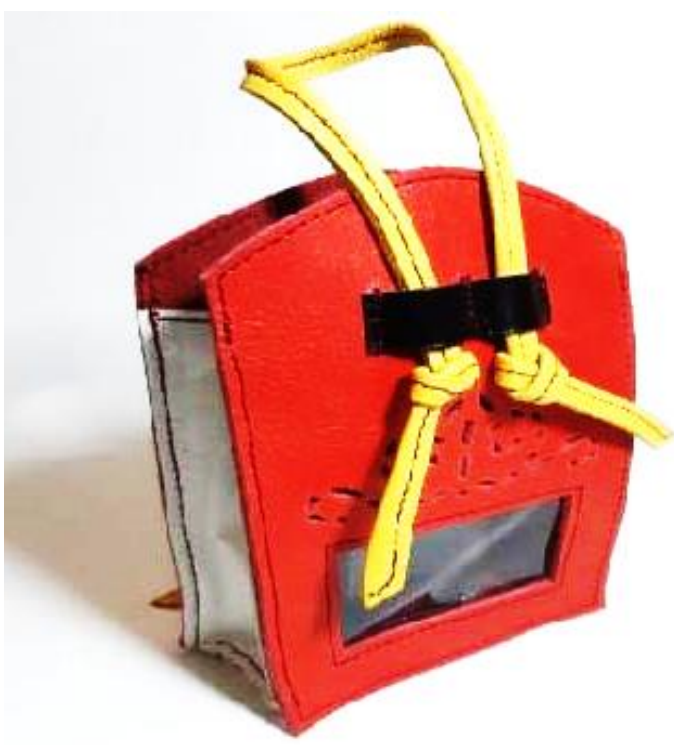

Gambar 22. Kemasan Model 1

(Sumber: Dokumentasi Agung Wicaksono)

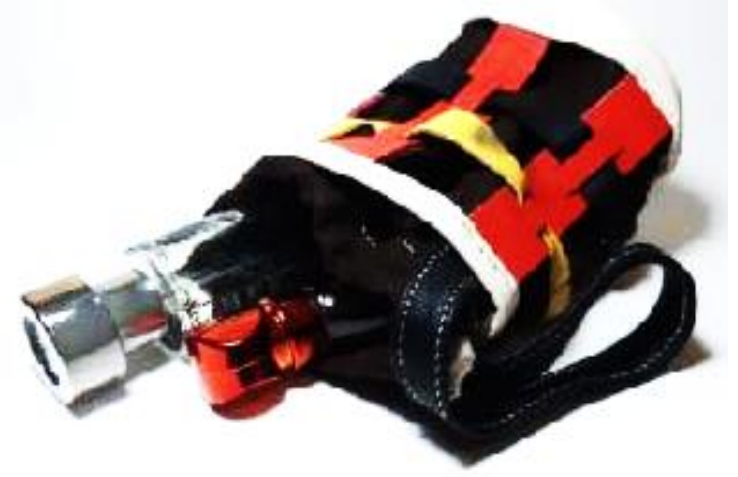

Gambar 23. Kemasan Model 2

(Sumber: Dokumentasi Agung Wicaksono)

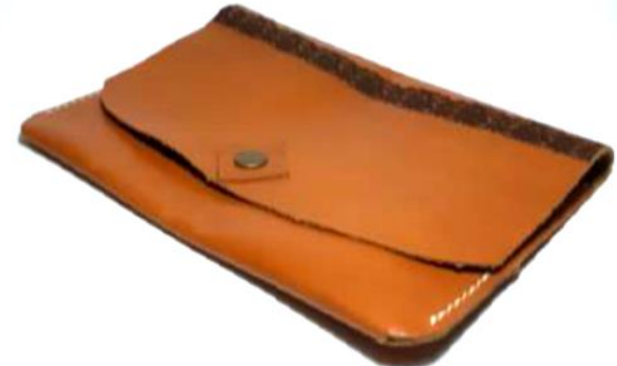

Gambar 24. Kemasan Model 3

(Sumber: Dokumentasi Agung Wicaksono)

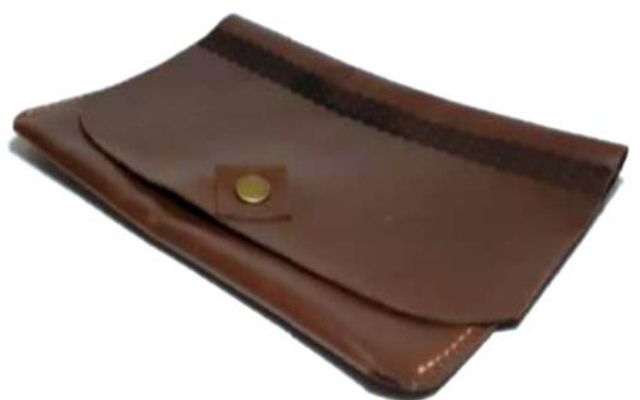

Gambar 25. Kemasan Model 4 (Sumber: Dokumentasi Agung Wicaksono)

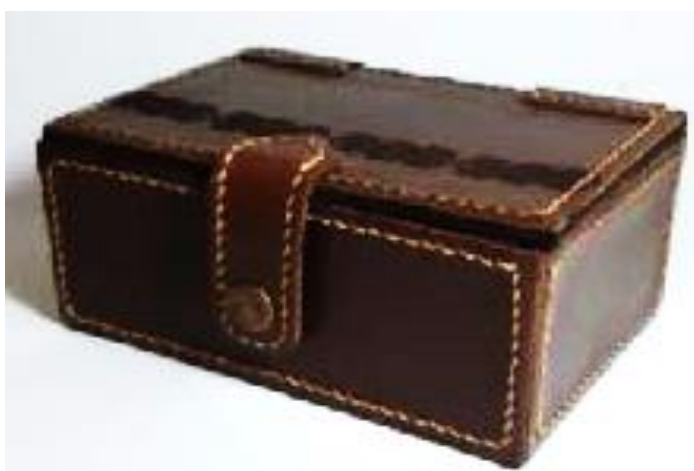

Gambar 26. Kemasan Model 5

(Sumber: Dokumentasi Agung Wicaksono)

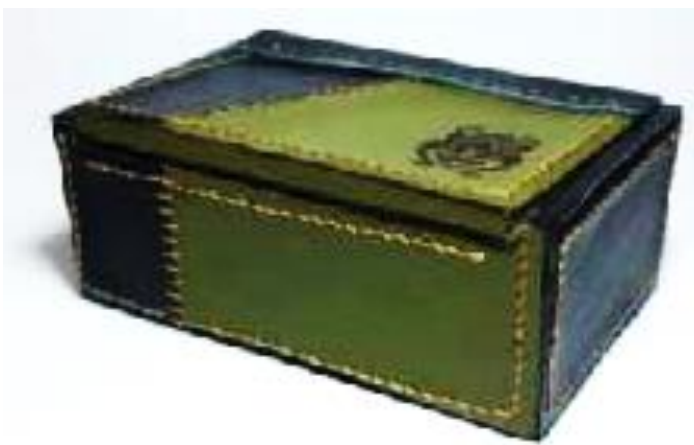

Gambar 27. Kemasan Model 6

(Sumber: Dokumentasi Agung Wicaksono) 


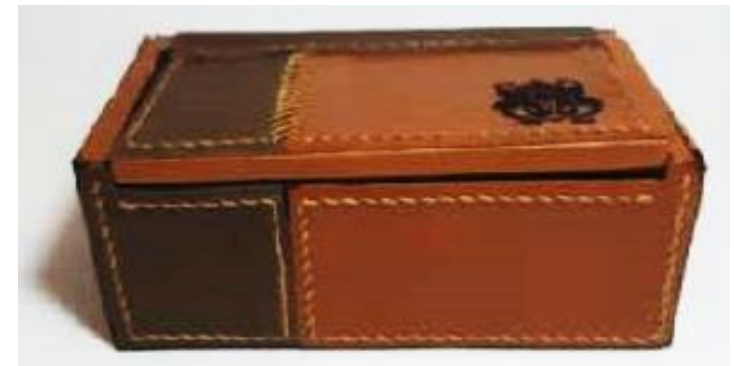

Gambar 28. Kemasan Model 7

(Sumber: Dokumentasi Agung Wicaksono)

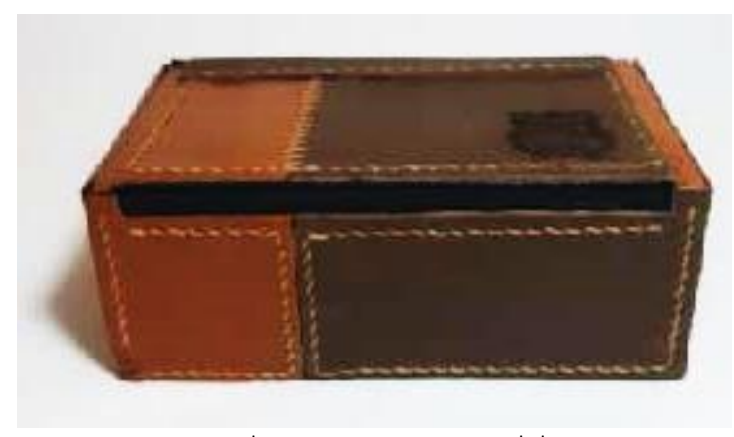

Gambar 29. Kemasan Model 8

(Sumber: Dokumentasi Agung Wicaksono)

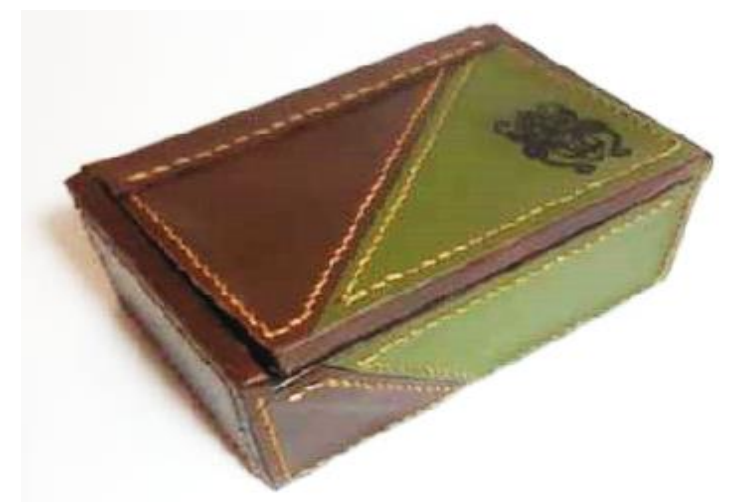

Gambar 30. Kemasan

(Sumber: Dokumentasi Agung Wicaksono)

\section{PENUTUP}

Perancangan ini diawali dengan pencarian data yang terkait dengan kemasan produk olahan kayu gaharu. Analisis dilakukan dengan menggunakan alat mood board yang mempermudah pemahaman korelasi antardata secara visual. Pertimbangan dalam analisis ini adalah bentuk, fungsi, dan makna. Bentuk terkait dengan estetika visual, fungsi terkait dengan operasionalisasi produk, dan makna terkait dengan motif-motif yang diaplikasikan pada produk. Pewujudan produk kemasan ini diharapkan mampu meningkatkan perekonomian mitra penelitian supaya bisa saling bekerja sama untuk mendapatkan keuntungan bersama.

\section{DAFTAR PUSTAKA}

\section{Artikel Jurnal}

Azah, MA Nor. dkk. 2013. "Classification of Agarwood (Gaharu) by Resin Content." Journal of Tropical Forest Science, Vol. 25, No. 2, 2013, JSTOR, www.jstor.org/stable/23617036.

Dimara, Petrus.A. 2011. "Teknik Pemanenan Gaharu oleh Masyarakat di Kabupaten Manokwari". Jurnal Becc, Vol. 13 No.1, 2011.

Setyaningsih, Dwi Wahyu. 2017. "Nilai Ekonomis Kulit Sapi sebagai Bahan Baku Pembuatan Alas Kaki". Media Soerjo Vol.20, No.1, April 2017.

Wicaksono, Agung. 2014. "Potensi Pengembangan Inovasi Desain Produk Kriya KUKM Indonesia di Era Industri Kreatif". dalam Jurnal Corak, Volume 3 No 1, Mei-Oktober 2014.

Wicaksono, Agung dan Budi Hartono. 2017. "Strategi Perancangan dengan Penerapan Ragam Hias Sulur Gelung Pada Produk Kriya untuk Pasar Global". dalam Jurnal Corak, Volume 6 Nomor 2, November 2017-April 2018.

Buku

Hendriyana, Husen. 2018. Metodologi Penelitian Penciptaan Karya. Bandung: Sunan Ambu Press.

Junaedi, Deni. 2016. Estetika Jalinan Subjek, Objek, dan Nilai. Yogyakarta: Artciv.

Sumartono. 2017. Metodologi Penelitian Kualitatif. Jakarta: Universitas Trisakti.

Wicaksono, Agung. 2009. Eksistensi Seni Kriya Indonesia di Era Gelombang Ekonomi Kreatif dalam Seni Kriya dan Kearifan Lokal: Dalam Lintasan Ruang dan Waktu. Editor Sri Kresnanto, Ikwan Setiyawan, dan Kasiyan. Yogyakarta: BIDISI. 